\title{
Calculation of the Chemical Composition of Air - PMMA Mixtures Thermal Plasmas
}

\author{
Kagoné Abdoul Karim*, Kohio Nièssan, Yaguibou Wêpari Charles, Koalaga Zacharie, \\ Zougmoré François
}

Department of Physics, University Joseph KI - ZERBO, Ouagadougou, Burkina Faso

\section{Email address:}

kagoneabdoul@yahoo.fr (K. A. Karim),kohioniessan@hotmail.fr(K. Nièssan), weparicharles@gmail.com (Y. W. Charles), kzacharie@hotmail.com (K. Zacharie), zougfran2013@gmail.com (Z. François)

${ }^{*}$ Corresponding author

\section{To cite this article:}

Kagoné Abdoul Karim, Kohio Nièssan, Yaguibou Wêpari Charles, Koalaga Zacharie, Zougmoré François. Calculation of the Chemical Composition of Air - PMMA Mixtures Thermal Plasmas. American Journal of Physical Chemistry. Vol. 9, No. 2, 2020, pp. 27-35. doi: $10.11648 /$ j.ajpc.20200902.12

Received: May 6, 2020; Accepted: May 27, 2020; Published: June 3, 2020

\begin{abstract}
Knowledge of the chemical composition of plasma is necessary for calculations and modeling in thermal plasmas. Indeed, from the knowledge of this composition we can calculate the thermodynamic properties, the transport coefficients and the radiative properties of a plasma medium. In this work, we propose to study at thermodynamic equilibrium the influence of pressure and of the PMMA polymer on the composition of the plasma of the Air - PMMA gas mixture. We are studying in particular the evolution of the density of the species created in this plasma as a function of temperature (5000 - $30000 \mathrm{~K})$ and pressure ( 1 bar - 10 bar) for variable mixtures at thermodynamic equilibrium. When we want to take into account a large number of chemical species in the plasma, two main methods are usually used, one is based on the law of mass action and the other on the minimization of Gibbs' free enthalpy. In our study, we used the mass action law method to calculate the composition of plasma. The results obtained show that when the plasma is in thermodynamic equilibrium the densities of the different species present in the plasma are only a function of the temperature, the pressure and the percentage of the polymer in the mixture.
\end{abstract}

Keywords: Electric Arc, Plasma, Chemical Composition, Density, Polymer, Circuit Breaker

\section{Introduction}

The electric arc which is generally defined as a high current electrical discharge has a wide variety of applications these days. Due to the wide range of its applications, it has given rise to numerous research works both on an experimental and theoretical level [1-35]. Among its applications, we can cite, among other things, lighting, welding, cutting, waste treatment and cutting of electric current. Indeed, the interruption of the electric current in certain switchgear, in particular the circuit breaker, is done from the electric arc. To cut the electric current, the opening of the circuit breaker contacts creates an electric arc which interacts with the surrounding environment. If in most applications, the arc must be maintained for as long as possible, its rapid extinction is sought in breaking devices. In fact, they are designed to provide manual or automatic control of electrical circuits (contactors) as well as protection of installations against short circuits (circuit breaker).

Certain cutting techniques are based on the rapid elongation of the arc between the contacts and others, on a rolling of the arc between two insulating parts. Numerous theoretical [3-4, 13, 18, 25, 27-35] and experimental [3, 10] studies have already been carried out on polymers. From studies carried out on laminated arcs with ablative walls [2-3], it appears that the PMMA polymer has interesting characteristics for breaking the electric current.

Our study is part of the interruption of the electric current by means of the electric arc used as energy dissipater by heat exchanges with the surrounding environment. As the cutting technique in air and compressed air [36] is widely used in low and medium voltage circuit breakers, in this work, we want to 
study the influence of the PMMA polymer on air breaking performance.

The breaking performance is partly linked to certain characteristics of the plasma formed in the circuit breaker at the time of breaking. Determining any characteristic of a plasma begins with knowing the equilibrium composition of the plasma.

This article is therefore devoted to the calculation of the equilibrium composition of plasmas of Air - PMMA mixtures at thermodynamic equilibrium. In addition to pure air and pure PMMA, the mixtures concerned are: $80 \%$ Air - 20\% PMMA; $50 \%$ Air - 50\% PMMA; 20\% Air - 80\% PMMA. The temperature range goes from $5000 \mathrm{~K}$ to $30000 \mathrm{~K}$ for pressures of 1 bar; 2 bar; 5 bar; 8 bar and 10 bar.

\section{Calculation Assumptions}

The calculation of the chemical composition of the Air PMMA plasma constitutes a first approach to the environment studied, allowing to know the evolution of the density of the different particles present, as a function of the temperature and the PMMA percentage. It is moreover necessary for the calculation of the thermodynamic properties and the transport coefficients of the plasma medium.

The calculation of the chemical composition was made with the following assumptions:

(i) The plasma is at local thermodynamic equilibrium;

(ii) The composition of the air is: oxygen $20 \%$, nitrogen $80 \%$;

(iii) The percentages of the various mixtures are percentages by volume.

PMMA is the abbreviation for the polymer of common name Plexiglas, composed of polymethyl methacrylate and whose chemical formula is $\mathrm{C}_{5} \mathrm{H}_{8} \mathrm{O}_{2}$. The basic atoms of air are oxygen $(\mathrm{O})$ and nitrogen $(\mathrm{N})$ and those of PMMA are carbon $(\mathrm{C})$, hydrogen $(\mathrm{H})$ and oxygen $(\mathrm{O})$. The basic atoms in the Air - PMMA mixture are therefore carbon $(\mathrm{C})$, hydrogen $(\mathrm{H})$, oxygen $(\mathrm{O})$ and nitrogen $(\mathrm{N})$. Given the range of temperatures considered $(5000 \mathrm{~K}$ to $30000 \mathrm{~K})$, the different chemical species that we have taken into account in the composition of plasmas are electrons, diatomic molecules, neutral atoms and their corresponding ions charged once or twice; be the following 32 particles: e, C, H, N, O, $\mathrm{C}_{2}, \mathrm{H}_{2}, \mathrm{~N}_{2}, \mathrm{O}_{2}, \mathrm{CH}, \mathrm{CO}, \mathrm{CN}, \mathrm{OH}, \mathrm{HN}$, $\mathrm{NO}, \mathrm{C}^{+}, \mathrm{H}^{+}, \mathrm{O}^{+}, \mathrm{N}^{+}, \mathrm{CH}^{+}, \mathrm{CO}^{+}, \mathrm{CN}^{+}, \mathrm{OH}^{+}, \mathrm{HN}^{+}, \mathrm{NO}^{+}, \mathrm{C}_{2}{ }^{+}, \mathrm{H}_{2}{ }^{+}$, $\mathrm{N}_{2}^{+}, \mathrm{O}_{2}^{+}, \mathrm{C}^{2+}, \mathrm{N}^{2+}$ and $\mathrm{O}^{2+}$.

In the rest of the article, the numerical density of the electrons will be represented by $n_{e}$ and those of other particles by their corresponding chemical symbols. As an example, the numerical density of hydrogen atoms will be noted $\mathrm{H}$.

\section{Method of the Plasma Chemical Composition Calculation}

Calculation of the chemical composition of plasma is done by the method based on the law of mass action. It is done using a system of equations, the number of which is determined by the number of chemical particles taken into account in the composition of the plasma. In this study, the number of chemical particles taken into account in the composition of the plasma being equal to 32 , then we will have a system of 32 equations with 32 unknowns. Some of these equations require knowledge of the internal partition functions of the different particles. Writing the equilibrium constants at constant pressure for each of the reactions as a function of the partition functions on the one hand and the numerical densities of the chemical particles on the other hand, provide a number equations of the system.

Solving the system of equations using the Newton-Raphson resolution method gives access to the chemical composition of the plasma.

Indeed, at thermodynamic equilibrium, the numerical densities of the different particles contained in the plasma are perfectly determined from a system of equations obtained by applying to the plasma the fundamental laws of thermodynamic.

(i) Ideal gas law

It assumes that all the plasma and each of its constituents behaves as a perfect gas. So it says:

$$
P=k T \sum_{i=1}^{v} n_{i}
$$

Where $P$ is the total pressure, $n$ the numerical density of the species $i, k$ the Boltzmann constant and $v$ is the number of particles.

(ii) Law of electrical neutrality

It is a law which translates the fact that the plasma is electrically neutral on the macroscopic scale:

$$
n_{e}-\sum_{i=1}^{v} Z_{i} n_{i, z_{i}}=0
$$

Where $n_{i, z_{i}}$ is the numerical density of heavy particles $i$ with the charge $Z_{i} e ; n_{e}$ the numerical density of the electrons.

(iii) Saha-Eggert's laws

They govern the balance between the number of atoms, ions and electrons per unit volume. For a reaction of the type $A \rightarrow A^{+}+e^{-}$, Saha-Eggert's law is written:

$$
S_{A}=\frac{n_{e} n_{A^{+}}}{n_{A}}=2\left(\frac{2 \pi m_{e} k T}{h^{2}}\right)^{\frac{3}{2}} \frac{\left(Q_{\text {int }}\right)_{A^{+}}}{\left(Q_{\text {int }}\right)_{A}} \exp \left(-\frac{E_{A}-\Delta E_{A}}{k T}\right)
$$

Where $m_{e}$ is the mass of the electron, $n_{A^{+}}$and $n_{A}$ are the numerical densities of the particles respectively $A^{+}$and $A .\left(Q_{\text {int }}\right)_{A^{+}}$is the internal partition function of the specie $A^{+}$and $(Q \text { int })_{A}$ that of the particle $A, E_{A}$ is the ionization energy of $A . \Delta E_{A}$ is the reduction of the ionization energy due to a phenomenon of plasma polarization at the macroscopic level. It depends on the charge and the numerical 
densities of the charged particles, as well as on the plasma temperature.

$S_{A}$ is called the ionization equilibrium constant. The specie $A$ can be either a neutral particle or a charged particle.

The expression of the ionization potential reduction proposed by Capitelli et al [3] is written:

$$
\Delta E_{J}=2\left(Z_{J}+1\right) e^{3}\left(\frac{\pi}{k T}\right)^{\frac{1}{2}}\left(n_{e}+\sum_{i} Z_{i}^{2} n_{i}\right)
$$

The summation relates to all the heavy charged particles. $Z_{J}$ is the number of charges of the specie $j$.

(iv) Laws of Guldberg and Waage

These equations translate the dissociation-recombination equilibria existing in the plasma. For an equation of the type $A B \rightarrow A+B$ ( $A$ may be the same as $B$ ); she is written:

$$
K_{A B}=\frac{n_{A} n_{B}}{n_{A B}}=\left(\frac{2 \pi k T}{h^{2}} \frac{m_{A} m_{B}}{m_{A B}}\right)^{\frac{3}{2}} \frac{\left(Q_{\mathrm{int}}\right)_{A}\left(Q_{\mathrm{int}}\right)_{B}}{\left(Q_{\mathrm{int}}\right)_{A B}} \exp \left(-\frac{E_{d}}{k T}\right)
$$

Where $n_{A}, m_{A},\left(Q_{\text {int }}\right)_{A}$ are respectively the numerical density, the mass and the internal partition function of the specie $A . E_{d}$ is the dissociation energy of the particle $A B$. $K_{A B}$ is called the dissociation equilibrium constant.

(v) Equations of basic elements proportions

The equations of proportions are equations which express the content of basic elements of the plasma. The basic elements are neutral atoms $(C, H, O, N)$ contained in the chemical formulas of gases giving rise to plasma.

\section{Particles Internals Partition Functions}

The partition functions of the different particles are essential for calculating the equilibrium composition of the plasma. They can be determined either from the literature (by numerical smoothing of the tabulated values), or using the formulas below.

(i) Internals partition functions of monoatomic particles

The relationship below is the general expression of the internal partition function of monoatomic species.

$$
Q_{\text {int }}(T)=\sum_{n} g_{n} \exp \left(-\frac{E_{n}}{k T}\right)
$$

The summation relates to all energy levels $E_{n}$ of statistical weight $g_{n}$. So that it is not divergent, we limit ourselves to $E_{n} \prec E_{i}-\Delta E_{i}, E_{i}$ being the ionization energy of the particle. The internal partition functions are generally known and tabulated according to the temperature and the reduction of the ionization energy $\Delta E_{i}$.

For the electrons we have: $Q_{\text {int }}=2$

(ii) Internals partition functions of diatomic particles

We can determine the internal partition functions of diatomic particles from Herzberg's formula

$$
Q_{\text {int }}=\sum_{n}^{n_{\max }} Q_{n}
$$

Where $Q_{n}$ is the partition function for the electronic state $n$ of the molecule and defined by:

$$
Q_{n}=\frac{k T}{h c \beta_{n} \sigma} \frac{g_{n} \exp \left(-\frac{\varepsilon_{n}}{k T}\right)}{\left[1-\exp \left(\frac{h c \omega_{n}}{k T}\right)\right]}
$$

Where $g_{n}, \varepsilon_{n}, \beta_{n}, \omega_{n}$ are respectively the statistical weight, the energy, the constant of rotation and the constant of vibration of the state $n$ of the molecule. $\sigma$ is a factor of symmetry $(\sigma=1$ for hetero nuclear molecules and $\sigma=2$ for homo nuclear). $h$ is Planck's constant and $c$ the speed of light. The parameters $\varepsilon_{n}, \beta_{n}, \omega_{n}$ are defined by:

$$
\begin{gathered}
\omega_{n}=\omega_{e}-\chi_{e} \omega_{e} \\
\beta_{n}=\beta_{e}-\frac{\alpha_{e}}{2} \\
\varepsilon_{n}=T_{e}+\frac{1}{2}\left(\omega_{e}-\frac{1}{2} \omega_{e} \chi_{e}\right)
\end{gathered}
$$

$\omega_{e}, \omega_{e} \chi_{e}, \beta_{e}, \alpha_{e}$ are constants depending on the state of vibration and rotation for a given state in the approximation of the harmonic oscillator and the rigid rotator. $T_{e}$ is the electronic energy of the state considered. These are known and tabulated constants. The values of $T e, \omega_{e}, \beta_{e}, \omega_{e} \chi_{e}$ and $\alpha_{e}$ for each electronic state $n$ of certain diatomic molecules are given by Herzberg. For other diatomic particles, the values of the different constants are recorded in the tables of Janaf [3]. In the expression $Q_{\text {int }}, n_{\max }$ is chosen as the electronic energy state $\varepsilon_{n_{\max }}$ lower than the dissociation energy of the molecule considered.

\section{Calculation of the Plasma Chemical Composition}

The total number of chemical particles taken into account in the composition of the plasma is thirty-two (32). It is therefore necessary to constitute a system of thirty-two (32) equations with thirty-two (32) unknowns.

(i) Formulation of the system of equations

The numerical densities of the chemical particles taken into account in the plasma are determined using a system of equations formed from:

a) the ideal gas law,

b) the law of electrical neutrality,

c) Saha-Eggert laws, 
d) Guldberg and Waage laws,

e) the proportions of the species present.

The ideal gas law gives the first equation:

$P=n k T$; where $n$ is the total numerical density of the particles present in the plasma and $k$ the Boltzmann's constant. We have:

$$
\begin{aligned}
& n=n_{e}+\mathrm{C}+\mathrm{C}^{+}+\mathrm{C}^{2+}+\mathrm{C}_{2}+\mathrm{C}_{2}^{+}+\mathrm{H}+\mathrm{H}^{+}+\mathrm{H}_{2}+\mathrm{H}_{2}^{+}+\mathrm{O}+\mathrm{O}^{+} \\
& +\mathrm{O}^{2+}+\mathrm{O}_{2}+\mathrm{O}_{2}^{+}+\mathrm{N}+\mathrm{N}^{+}+\mathrm{N}^{2+}+\mathrm{N}_{2}+\mathrm{N}_{2}^{+}+\mathrm{CH}+\mathrm{CO}+\mathrm{CN} \\
& +\mathrm{OH}+\mathrm{HN}+\mathrm{NO}+\mathrm{CH}^{+}+\mathrm{CO}^{+}+\mathrm{CN}^{+}+\mathrm{OH}^{+}+\mathrm{HN}^{+}+\mathrm{NO}^{+}
\end{aligned}
$$

With $n_{e}$ the numerical density of electrons.

The law of electrical neutrality gives the following second equation:

$$
\begin{aligned}
& n_{e}=\mathrm{C}^{+}+2 \mathrm{C}^{2+}+\mathrm{C}_{2}^{+}+\mathrm{H}^{+}+\mathrm{H}_{2}^{+}+\mathrm{O}^{+}+2 \mathrm{O}^{2+}+\mathrm{O}_{2}^{+}+\mathrm{N}^{+} \\
& +2 \mathrm{~N}^{2+}+\mathrm{N}_{2}^{+}+\mathrm{CH}^{+}+\mathrm{CO}^{+}+\mathrm{CN}^{+}+\mathrm{OH}^{+}+\mathrm{HN}^{+}+\mathrm{NO}^{+}
\end{aligned}
$$

Saha-Eggert's laws define 17 equilibrium constants corresponding to the 17 ionization reactions taking place in plasma. Consequently, the relation (3) applied to the 17 ionization reactions gives 17 equations.

The laws of Guldberg and Waage through the written relation for the dissociation of diatomic particles $\mathrm{C}_{2}, \mathrm{H}_{2}, \mathrm{O}_{2}, \mathrm{~N}_{2}, \mathrm{CH}, \mathrm{CO}, \mathrm{CN}, \mathrm{OH}, \mathrm{HN}$ and $\mathrm{NO}$, allows to establish 10 equations relating to the equilibrium of the ten (10) dissociation reactions taking place in the plasma.

The above laws thus provide a system of 29 equations with 32 unknowns.

To this system, we add additional equations defining the proportions of carbon atom $(x)$, hydrogen atom $(y)$, oxygen atom $(z)$ and nitrogen atom $(t)$.

In case the variables $x, y, z$ and $t$ are all non-zero, we can write three (3) independent proportion equations. Is:

$$
\begin{aligned}
& \frac{x}{y}=\frac{2 C_{2}+2 C_{2}^{+}+C+C^{+}+C^{2+}+\mathrm{CH}+\mathrm{CO}+\mathrm{CN}+\mathrm{CH}^{+}+\mathrm{CO}^{+}+\mathrm{CN}^{+}}{2 \mathrm{H}_{2}+2 \mathrm{H}_{2}^{+}+\mathrm{H}+\mathrm{H}^{+}+\mathrm{CH}+\mathrm{OH}+\mathrm{HN}+\mathrm{CH}^{+}+\mathrm{OH}^{+}+\mathrm{HN}^{+}} \\
& \frac{y}{z}=\frac{2 \mathrm{H}_{2}+2 \mathrm{H}_{2}^{+}+\mathrm{H}+\mathrm{H}^{+}+\mathrm{CH}+\mathrm{HO}+\mathrm{HN}+\mathrm{CH}^{+}+\mathrm{HO}^{+}+\mathrm{HN}^{+}}{2 \mathrm{O}_{2}+2 \mathrm{O}_{2}^{+}+\mathrm{O}+\mathrm{O}^{+}+\mathrm{O}^{2+}+\mathrm{CO}+\mathrm{OH}+\mathrm{ON}+\mathrm{CO}^{+}+\mathrm{OH}^{+}+\mathrm{ON}^{+}} \\
& \frac{z}{t}=\frac{2 \mathrm{O}_{2}+2 \mathrm{O}_{2}^{+}+\mathrm{O}+\mathrm{O}^{+}+\mathrm{O}^{2+}+\mathrm{CO}+\mathrm{OH}+\mathrm{ON}+\mathrm{CO}^{+}+\mathrm{OH}^{+}+\mathrm{ON}^{+}}{2 \mathrm{~N}_{2}+2 \mathrm{~N}_{2}^{+}+\mathrm{N}+\mathrm{N}^{+}+\mathrm{N}^{2+}+\mathrm{CN}+\mathrm{NH}+\mathrm{NO}+\mathrm{CN}^{+}+\mathrm{NH}^{+}+\mathrm{NO}^{+}}
\end{aligned}
$$

We thus obtain a system of thirty - two (32) equations with thirty - two (32) unknowns. The unknowns are the numerical densities of the particles taken into account in the plasma.

(ii) Solving the system of equations

The system of thirty - two (32) equations with thirty - two unknowns (32) obtained is a nonlinear system. Using the relations defining the equilibrium constants of ionization and dissociation, we can by substitution reduce the system to a nonlinear system of five (5) equations with five (5) unknowns. The five (5) unknowns are the numerical densities of the electrons $\left(n_{e}\right)$, carbon atoms $(C)$, hydrogen atoms $(H)$, oxygen atoms $(O)$ and nitrogen atoms $(N)$. The resolution of the system is then carried out using an iterative method (Newton-Raphson method), based on the linearization of the nonlinear system. We then obtain the numerical densities $n_{e}, C, H, O$ and $N$, and therefore the concentrations of the other particles.

\section{Results and Discussions}

The equilibrium chemical composition was calculated for plasmas of the following different mixtures of air and PMMA:

a) $100 \%$ Air,

b) $80 \%$ Air - 20\% PMMA,

c) $50 \%$ Air - 50\% PMMA,

d) $20 \%$ Air - $80 \%$ PMMA,

e) $100 \%$ PMMA.

The temperature range goes from $5000 \mathrm{~K}$ to $30000 \mathrm{~K}$ for pressures of 1 bar; 2 bar; 5 bar; 8 bar and 10 bar.

Figures 1 to 5 respectively give the results of the equilibrium composition calculations of plasmas of: $100 \%$ Air; 80\% Air - 20\% PMMA; 50\% Air - 50\% PMMA; 20\% Air - $80 \%$ PMMA and 100\% PMMA at thermodynamic equilibrium and at a pressure of 1 bar. These different figures give the variations of the five plasmas compositions as a function of temperature, at a pressure of 1 bar. The various results obtained show that whatever the mixture, the composition of the plasma obtained changes in three phases as a function of the temperature. The first phase is characterized by the predominance of diatomic particles for temperatures below $7500 \mathrm{~K}$. A second phase between the temperatures of $7500 \mathrm{~K}$ and $15000 \mathrm{~K}$ marked by a strong presence of neutral monoatomic particles coming from the reactions of dissociation of diatomic particles. At the end, the third phase going from $15000 \mathrm{~K}$ to $30000 \mathrm{~K}$ where the neutral particles gradually become negligible compared to the electrons and the ionized particles. For temperatures above $25000 \mathrm{~K}$, the strong presence of charged particles makes it possible to consider the plasma as almost completely ionized.

By observing all of the curves in Figures 1 to 5 , the following remarks can be made:

1) The numerical densities of neutral diatomic particles decrease rapidly with temperature. This decrease is explained by the fact that these particles have low dissociation energy values.

2) For plasmas containing the elements carbon and oxygen, we note that the numerical density of the $\mathrm{CO}$ particle is relatively high at low temperatures. This is explained by the fact that this particle has a high dissociation energy. This results in low numerical densities of carbon atoms $\mathrm{C}$ and oxygen $\mathrm{O}$, for temperatures below $7000 \mathrm{~K}$.

3 ) It should be noted in general that for mixtures containing the elements carbon, hydrogen, oxygen and nitrogen, the numerical densities of the neutral atomic particles $\mathrm{C}, \mathrm{H}$, $\mathrm{O}$ and $\mathrm{N}$ present in the plasma depend on their initial percentage. But in particular, the numerical density of the hydrogen atom $\mathrm{H}$ remains the most important in the plasmas of these mixtures. This is because the diatomic 
particles containing hydrogen have the lowest dissociation energies.

4) The production of electrons at low temperature is entirely due to the ionization of carbon $\mathrm{C}$ for mixtures containing this element. This is related to the low value of the ionization energy of carbon compared to that of other neutral monoatomic particles. On the other hand, for $100 \%$ Air plasma where there is no carbon element, the production of electrons at low temperature is due to the ionization of the diatomic particle NO.

5) Apart from the $100 \%$ Air plasma, the ionization of the hydrogen atoms $\mathrm{H}$ constitutes the most important part in the numerical density of the electrons in the plasma, for temperatures higher than $15000 \mathrm{~K}$. For the plasma of $100 \%$ Air, it is the ionization of the nitrogen atoms $\mathrm{N}$ which represents the most important part. In all mixtures, the contribution of twice ionized particles is appreciable only at very high temperatures.

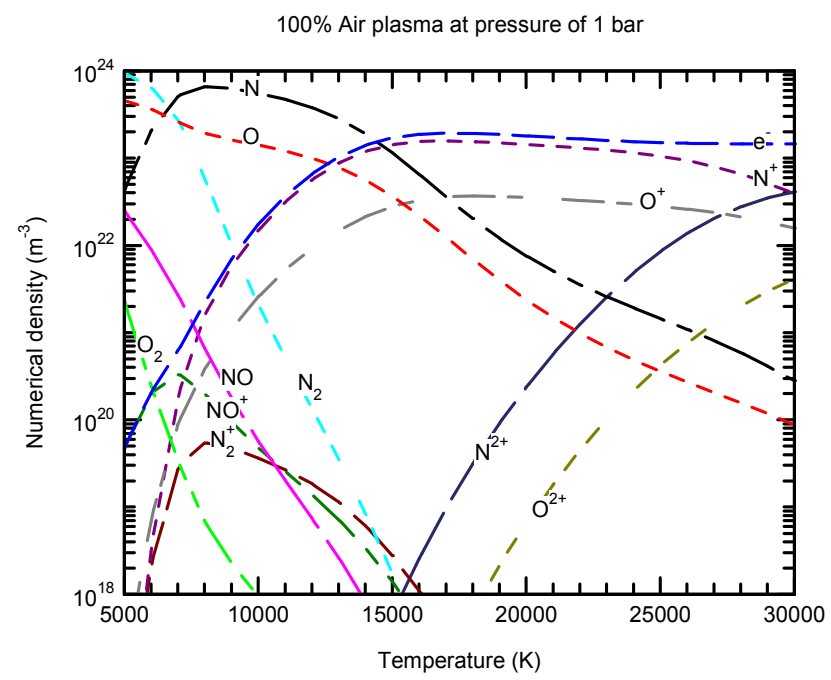

Figure 1. Variation of the $100 \%$ Air plasma composition as a function of temperature, at a pressure of 1 bar.

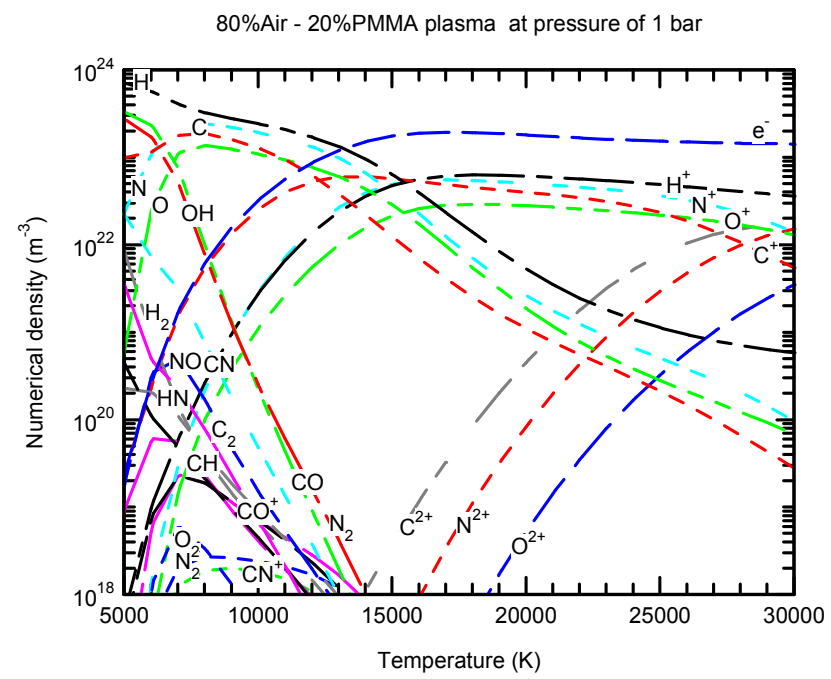

Figure 2. Variation of the composition $80 \%$ Air - 20\% PMMA plasma as a function of temperature, at a pressure of 1 bar.

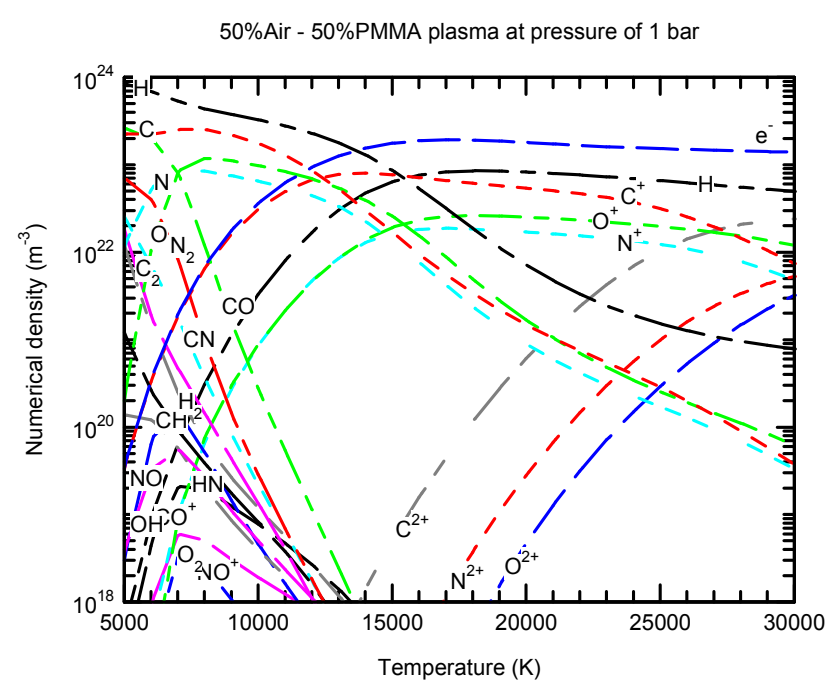

Figure 3. Variation of the 50\% Air - 50\% PMMA plasma composition as a function of temperature, at a pressure of 1 bar.

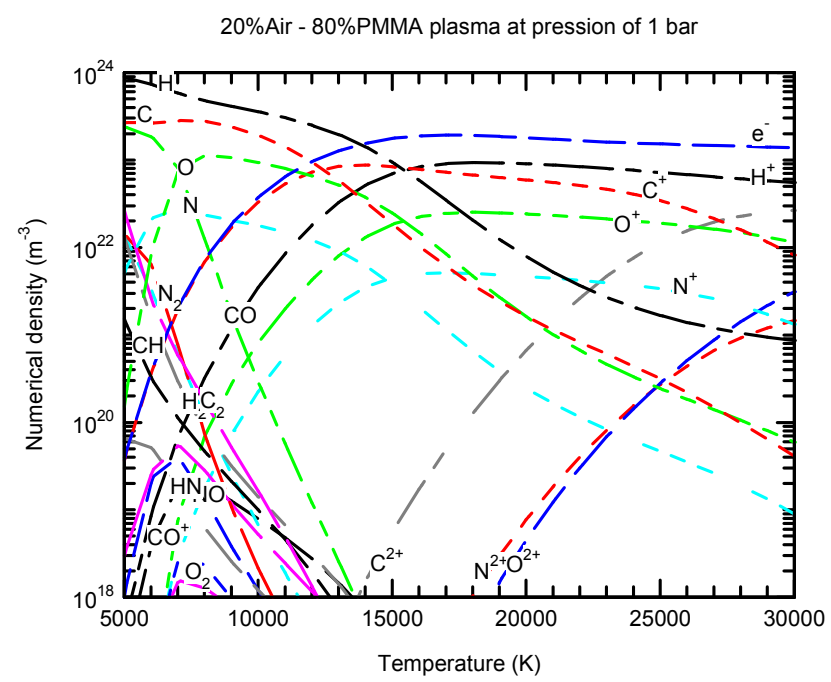

Figure 4. Variation of the 20\% Air - $80 \%$ PMMA plasma composition as a function of temperature, at a pressure of 1 bar.

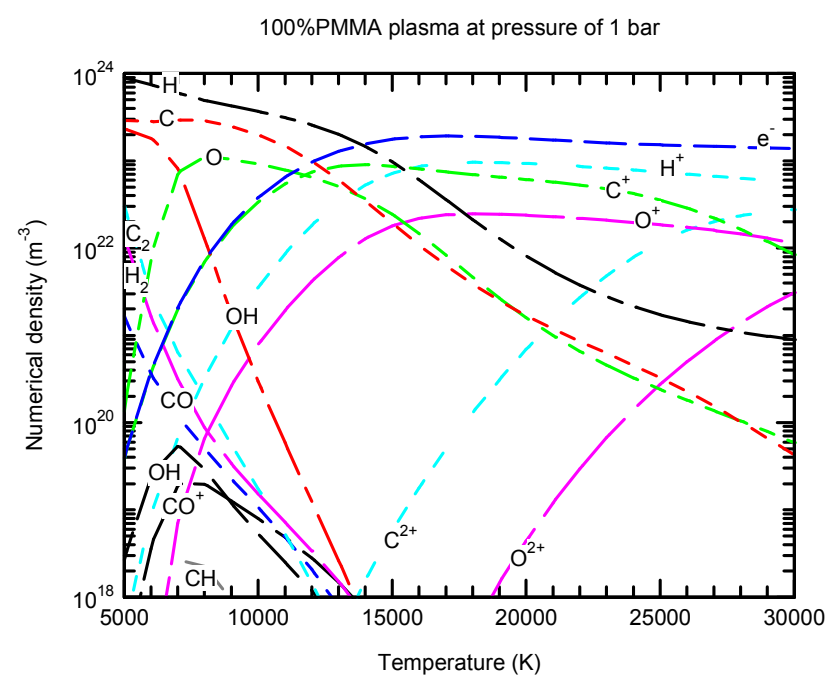

Figure 5. Variation of the 100\% PMMA plasma composition as a function of temperature, at a pressure of 1 bar. 
Figures 6 to 9 show the equilibrium composition of the Air PMMA mixture plasma, as a function of the PMMA percentage in the mixture, at thermodynamic equilibrium and at the pressure of 1 bar. These different figures give the variations of the numerical densities of the particles in the plasma of the mixture as a function of the PMMA percentage.

These results show the influence of the PMMA on the plasma composition of the mixture. In each figure, the arrows indicate the increasing direction of the PMMA percentage in the mixture.

From the analysis of all of the curves of Figures 6 to 10, it emerges the following:

1) The numerical densities of neutral diatomic particles $\mathrm{C}_{2}$, $\mathrm{H}_{2}, \mathrm{CH}$ in the plasma grow with the percentage of PMMA in the mixture while that of the neutral diatomic particles $\mathrm{O}_{2}, \mathrm{~N}_{2}, \mathrm{CO}, \mathrm{CN}, \mathrm{HO}$ and $\mathrm{NO}$ decrease.

2) The densities of neutral monoatomic particles $\mathrm{C}$ and $\mathrm{H}$ in the plasma increase with the rate of PMMA in the mixture while those of neutral monoatomic particles $\mathrm{O}$ and $\mathrm{N}$ decrease. This can be explained by the evolution of the numerical densities of diatomic particles $\mathrm{C}_{2}, \mathrm{H}_{2}$, $\mathrm{O}_{2}, \mathrm{~N}_{2}, \mathrm{CO}, \mathrm{CN}, \mathrm{HO}$ and $\mathrm{NO}$ in plasma depending on the PMMA rate.

3) The numerical density of the electrons in the plasma increases as a function of the PMMA percentage in the mixture for temperature values lower than $14000 \mathrm{~K}$. However, for the values of temperatures higher than $14000 \mathrm{~K}$, it tends towards a limit value independently of the PMMA percentage.

4) The numerical densities of the ionized monoatomic particles $\mathrm{C}^{+}$and $\mathrm{H}^{+}$increase while those of $\mathrm{O}^{+}$and $\mathrm{N}^{+}$ decrease in plasma with the PMMA percentage in the mixture. This is linked to the evolution of the numerical densities of particles $\mathrm{C}, \mathrm{H}, \mathrm{O}$ and $\mathrm{N}$ in the plasma as a function of the PMMA percentage in the mixture.

5) Double ionized monoatomic particles $\mathrm{O}^{2+}$ and $\mathrm{N}^{2+}$ have numerical densities that decrease during the numerical density of $\mathrm{C}^{2+}$ increases in plasma when the rate of PMMA increases in the mixture.

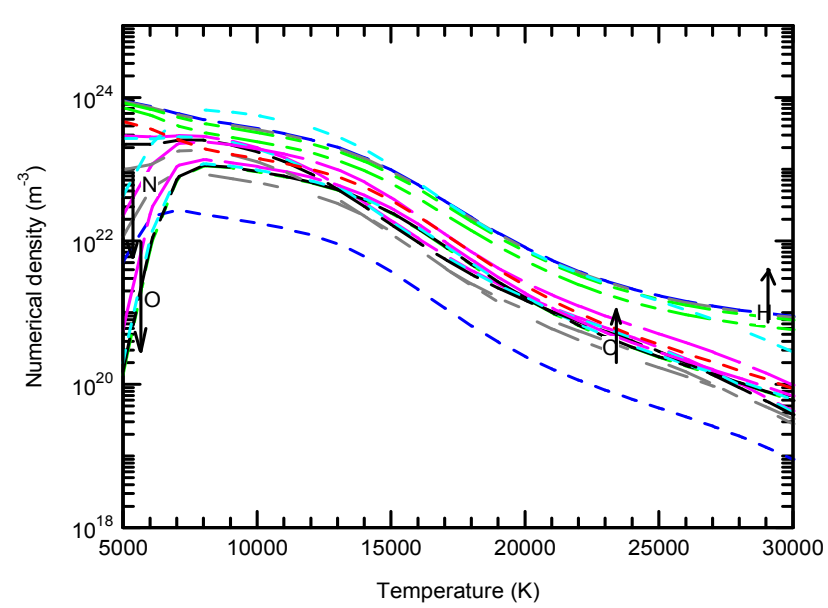

Figure 6. Variation of the neutral monoatomic particles numerical densities, as a function of temperature, for the various mixtures at a pressure of 1 bar.

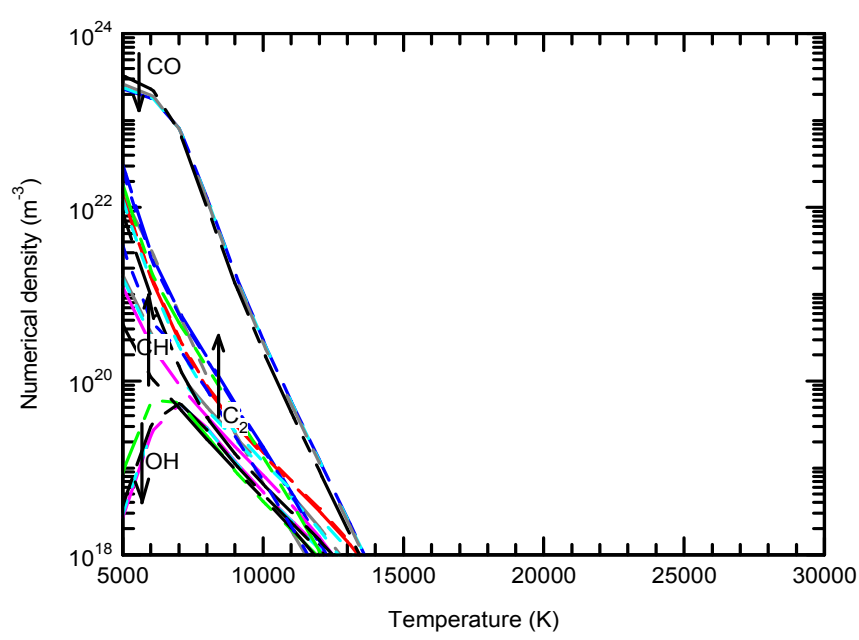

Figure 7. Variation of the neutral diatomic particles numerical densities, as a function of temperature, for the various mixtures at a pressure of 1 bar.

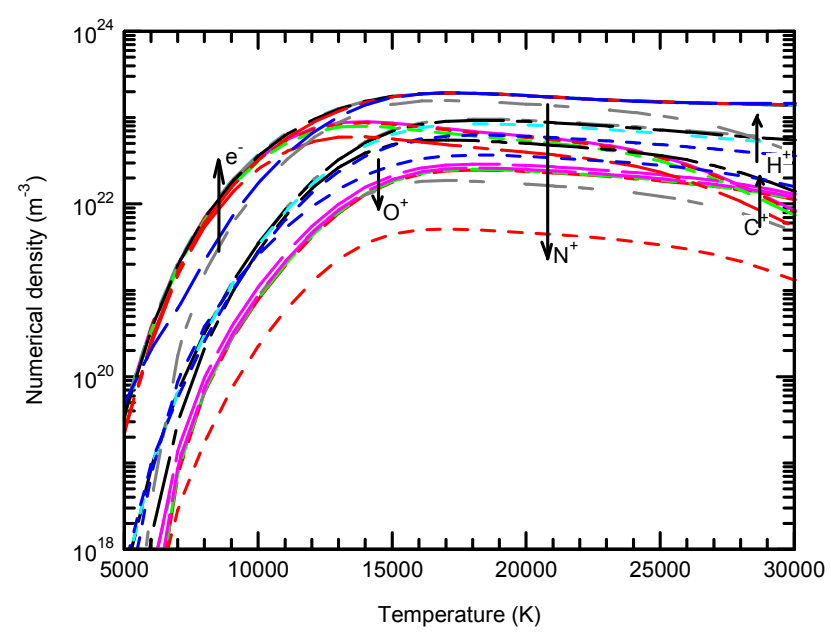

Figure 8. Variation of electrons and atomic particles once ionized numerical densities, as a function of temperature, for the various mixtures at a pressure of 1 bar.

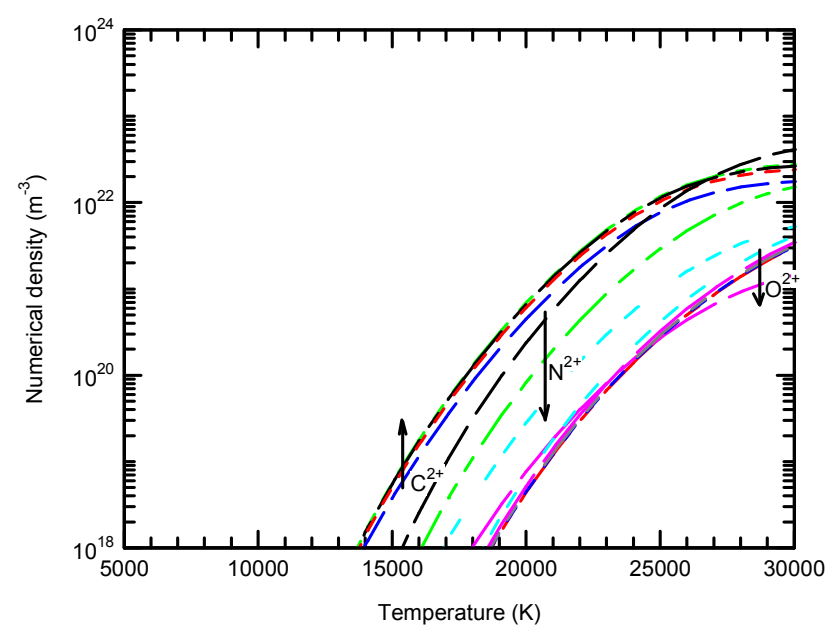

Figure 9. Variation of the twice ionized monoatomic particles numerical densities, as a function of temperature, for the various mixtures at a pressure of 1 bar.

To show the influence of pressure, we have limited 
ourselves to the case of the plasma of the $50 \%$ Air $-50 \%$ PMMA mixture to give the most significant results. The remarks made on the influence of pressure on the composition of this plasma are valid for the other plasmas.

We have reported in Figures 10 to 13, the equilibrium composition of this plasma, for pressures of 1 bar, 2 bar, 5 bar, 8 bar and 10 bar. In each figure, the arrows indicate the increasing direction of pressure.

We note that the numerical densities of neutral monoatomic particles are increasing functions of pressure beyond a value of temperature. Below this temperature value, the numerical densities decrease as the pressure increases. For neutral diatomic particles, their numerical densities increase with pressure.

These remarks can be explained by the following fact: at constant temperature, the number of particles per unit of volume increases when the pressure increases in accordance with the ideal gas equation $\mathrm{P}=\mathrm{nkT}$. The average energy per particle will therefore decrease. As in plasma, dissociation and ionization reactions are endothermic chemical reactions, they are more difficult to perform for a given temperature when the pressure increases. These reactions therefore take place at higher temperatures the higher the pressure.

There is a marked increase in the numerical densities of the ions $\mathrm{N}^{+}, \mathrm{C}^{+}$and $\mathrm{O}^{+}$as a function of the pressure above temperatures respectively $\mathrm{T}=17000 \mathrm{~K}, \mathrm{~T}=20000 \mathrm{~K}$ and $\mathrm{T}=$ $24000 \mathrm{~K}$, linked to the decrease in the numerical densities of $\mathrm{N}^{2+}, \mathrm{C}^{2+}$ and $\mathrm{O}^{2+}$. We notice that this phenomenon does not concern the ion $\mathrm{H}^{+}$because there is no ion $\mathrm{H}^{2+}$.

At very high temperatures, the numerical densities of electrons and $\mathrm{H}^{+}$tend towards limit values independent of pressure. The shapes of the numerical density curves of $\mathrm{C}^{+}, \mathrm{O}^{+}$ and $\mathrm{N}^{+}$show that we can expect a similar development for pressures above 10 bar. In other words, the numerical densities of these particles will be very low at this same temperature range for very high pressure values.

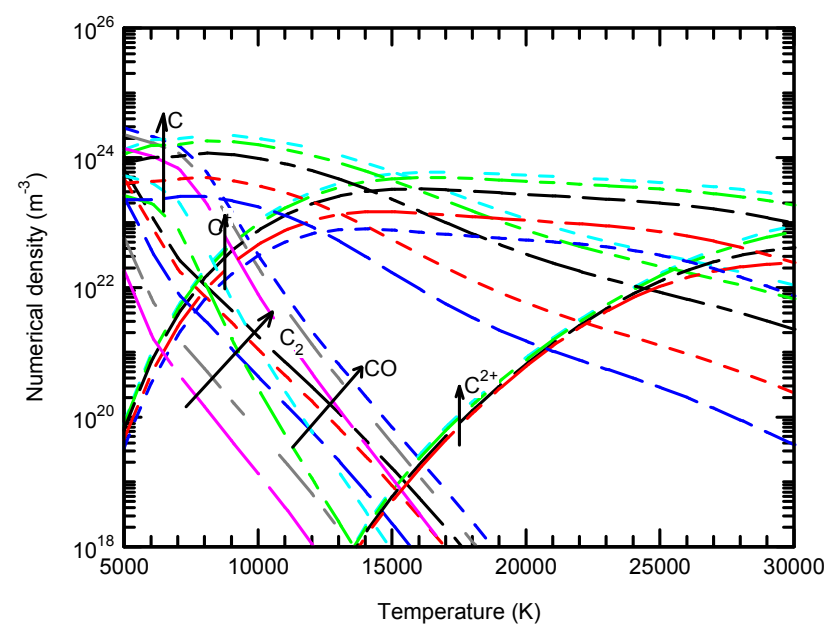

Figure 10. Variation of numerical densities of particles $C, C^{+}, C_{2}, C O$ and $C^{2+}$, as a function of temperature, for the different pressure values.

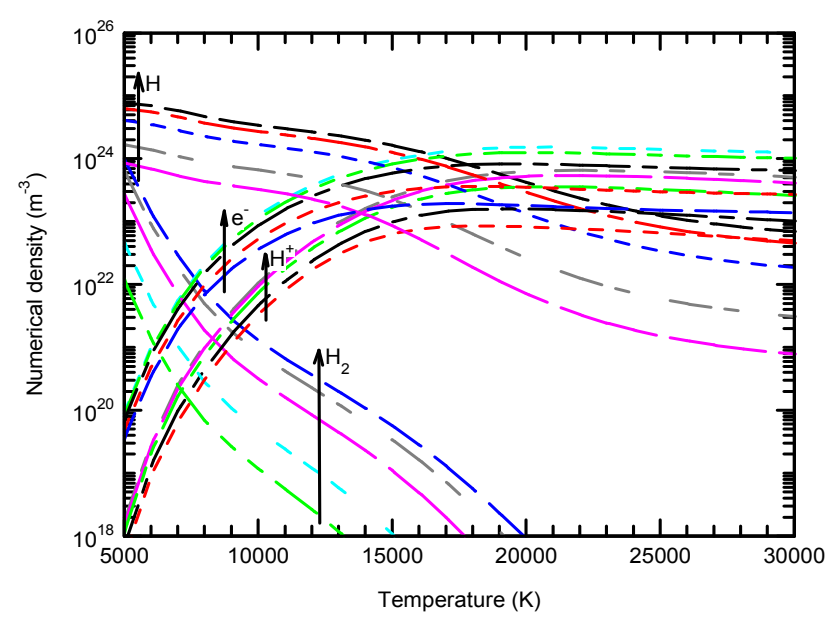

Figure 11. Variation of numerical densities of particles $e^{-}, \mathrm{H}_{1} \mathrm{H}^{+}$and $\mathrm{H}_{2}$, as a function of temperature, for the different pressure values.

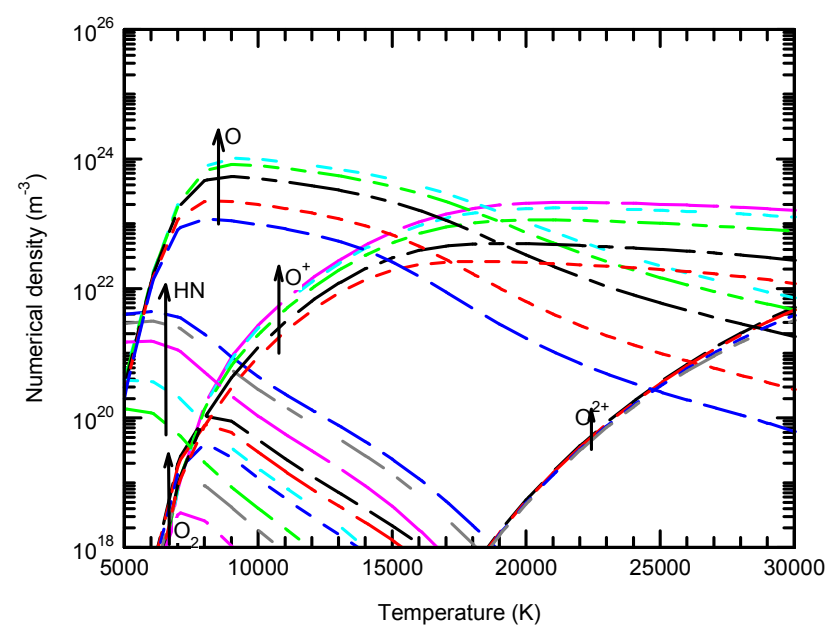

Figure 12. Variation of numerical densities of particles $\mathrm{O}, \mathrm{O}^{+}, \mathrm{O}_{2}, \mathrm{HN}$ and $\mathrm{O}^{2+}$, as a function of temperature, for the different pressure values.

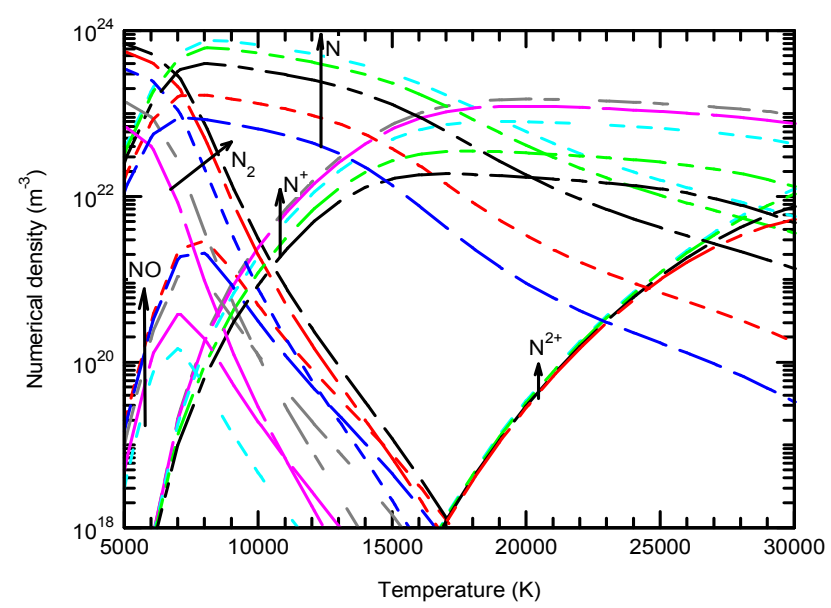

Figure 13. Variation of numerical densities of particles $N, N^{+}, N_{2}, N O$ and $N^{2+}$, as a function of temperature, for the different pressure values.

\section{Conclusion}

In this article, we have determined the equilibrium composition of plasmas of Air - PMMA mixtures. The 
mixtures that are the subject of the study are the mixtures of $80 \%$ Air -20\% PMMA, 50\% Air - 50\% PMMA and 20\% Air - 80\% PMMA. In addition to these mixtures, we also calculated the equilibrium composition of the plasmas of $100 \%$ Air and $100 \%$ PMMA. The temperature range considered is from $5000 \mathrm{~K}$ to $30000 \mathrm{~K}$. The pressure values of 1 bar, 2 bar, 5 bar, 8 bar and 10 bar have been used to show the influence of the pressure on the equilibrium composition plasma. The plasma equilibrium composition is calculated using the thermodynamic equilibrium law of mass action. The results of the calculations clearly show the evolution of the plasma composition in three phases depending on the temperature. The numerical densities of the neutral monoatomic particles $\mathrm{C}$ and $\mathrm{H}$ increase while those of $\mathrm{O}$ and $\mathrm{N}$ decrease well in the plasma with the percentage of PMMA in the mixture. The numerical density of the electrons in the plasma increases as a function of the percentage of PMMA in the mixture for temperature values below $14000 \mathrm{~K}$. However, for temperature values above $14000 \mathrm{~K}$, it tends towards a limit value independently of the PMMA percentage. For a given temperature, pressure has the main effect of increasing the numerical densities of the particles in the plasma. The increase in pressure leads to a delay in the dissociation and ionization reactions. In other words, these reactions are carried out at higher temperatures when the pressure increases.

Increasing the numerical density of hydrogen in plasma could have advantages in breaking the electrical current in the circuit breaker, but many other plasma parameters should be studied in order to confirm this.

\section{References}

[1] A. Blondel, "Sur le phénomène de l'arc électrique". J. Phys. Theor. Appl., 1897, 6 (1), pp. 513-520.

[2] B. Cheminat, "Influence de l'ablation des parois sur les caractéristiques d'un arc électrique laminé ", Revue Phys. Apll. 24 (1989) $277-284$.

[3] Z. Koalaga, "Contribution à l'étude expérimentale et théorique des plasmas d'arcs électriques laminés". Thèse de doctorat d'université, Clermont Fd 1991.

[4] V. V. Nossov, B. Hage, B. Jusselin and C. Fiévet, "Simulation of the Thermal Radiation Effect of an Arc on Polymer Walls in Low-Voltage Circuit Breakers", Technical Physics, 2007, Vol. 52, No. 5, pp. 651-659.

[5] P. André, W. Bussière, E. Duffour, L. Brunet and J. M. Lombard, "Effects of dielectric on arc plasma pressure and ablation measurement in high - power apparatus", IEEE transactions on magnetic, vol. 39, No.1, January 2003.

[6] B. Cheminat et P. Andanson, "La conduction dans la colonne d'un arc electrique contamine par des vapeurs de cuivre", J. Phys. D: Appl. Phys. 18 (1985) 2183-2192.

[7] B. Cheminat, R. Gadaud et P. Andanson,"Vaporisation d'une anode en argent dans le plasma d'un arc électrique", J. Phys. D: Appl. Phys. 20 (1987) 444-452.

[8] H. Ouajji, B. Cheminat et P. Andanson, "Modélisation de la colonne d'un arc électrique en présence de vapeur de cuivre", J. Phys. D: Appl. Phys. 20 (1987) 635-638.

[9] P. Andanson, A. Lefort et J Roche, "Erosion des contacts électriques sous l'effet d'un arc électrique de forte intensité , J. Phys D: Appl. Phys., Vol. 12, 1979.

[10] B. Cheminat et P. Andanson, "Etude expérimentale d'une décharge d'arc électrique contaminée par des vapeurs d'isolants, Revue Phys. Appl. 21 (1986) 187-193.

[11] F. Baudoin, J-J. Gonzalez and P. Checchin, "Study of the curvature of the electrical arc in low voltage breaking devices: influence of the external magnetic field", J. Phys. D: Appl. Phys. 38 (2005) 3778-3791.

[12] P. Andanson et B. Cheminat, "Isothermes d'une colonne d'arc électrique au voisiinage immédiat de la cathode", J. Phys. D: Appl. Phys.. 15 (1982) L27-30.

[13] M. Abbaoui and B. Cheminat, "Determination of characteristics of an electric arc plasma contaminated by vapors from insulators", IEES Transactions on Plasma Science, vol. 16. N. 1, February 1991.

[14] H. Salihou, M. Abbaoui, A. Lefort and R. Auby, "Determination of the power lost by I conduction into the cathode at low current arc", J. Phys. D: Appl. Phys. 28 (1995) 1883-1887.

[15] B. Melouki, M. Lieutier and A. Lefort, "The correlation between luminous and electric arc characteristics", J. Phys. D: Appl. Phys. 29 (1996) 2907-2914.

[16] H. Salihou, J. P. Guillot, M. Abbaoui and A. Lefort, "Anode parameters of short arcs at low current”, J. Phys. D: Appl. Phys. 29 (1996) 2915-2921.

[17] J. Rossignol, S. Clain and M. Abbaoui, "The modelling of the cathode sheath of an electrical arc in vacuum", J. Phys. D: Appl. Phys. 36 (2003) 1495-1503

[18] Z. Koalaga, "Influence of the choice of internal temperatures on the compositionof $\mathrm{CxHyOzNt}$ plasmas out of thermodynamic equilibrium: Application to $\mathrm{CH}_{2}$ plasma", Physics of Plasmas. Vulume 9, Number 11. November 2002.

[19] Z. Koalaga, "Composition d'équilibre des plasmas de $\mathrm{H}_{2}, \mathrm{O}_{2}$ et $\mathrm{N}_{2}$ hors équilibre thermique", Can. J. Phys. 81: 1095-1108 (2003).

[20] F. Bendjebbari, P. André, M. Benbakkar, D. Rochette, S. Flazi, D. Vacher, "Plasma Formed in Argon, Acid Nitric and Water Used in Industrial ICP Torches", Plasma Science and Technology, Vol. 14, No. 8, Aug. 2012.

[21] P. Andanson et B. Cheminat, "Contamination d'un plasma d'argon par des vapeurs anodiques de cuivre", Revue de Physique Appliquée, Tome 14, août 1979 p 775.

[22] P. Andanson et A. Lefort, "Calcul de l'érosion par vaporisation au niveau de la tache cathodique”, J. Phys. D: Appl. Phys., 17 (1984) 2377-2386.

[23] M. Abbaoui, B. Cheminat et P. Andanson, "Influence de la nature du metal sur la conductivite d'un plasma argon-metal", J. Phys. D: Appl. Phys. 18 (1985) L159-L165.

[24] A Lefort, M J Parizet, S E El-Fassi and M Abbaoui, "Erosion of graphite electrodes", J. Phys. D: Appl. Phys. 26 (1993) 1239-1243. 
[25] P. Andre, "Composition and thermodynamic properties of ablated vapours of PMMA, PA6-6, PETP, POM and PE", J. Phys. D: Appl. Phys. 29 (1996) 1963-1972.

[26] H. Ouajji, B. Cheminat et P. Andanson, "Composition et conductivité d'un plasma air-cuivre”, J. Phys. D: Appl. Phys. 19 (1986) 1903-1916.

[27] E. Duffour, P. Malfreyt, "Structure and thermodynamic properties from molecular dynamics simulations of the polyethylene crystal”, Polymer 43 (2002) 6341-6349.

[28] P André, "The influence of graphite on the composition and thermodynamic properties of plasma formed in ablated vapour of PMMA, PA6-6, PETP, POM and PE used in circuit-breakers", J. Phys. D: Appl. Phys. 30 (1997) 475-493.

[29] M. Abbaoui, Z. Koalaga et A. Lefort, "Composition et coefficients de transports des plasmas de matériaux plastiques (polymères) , Can. J. Phys. 71.1291 (1993).

[30] M. Abbaoui, Z. Koalaga et A. Lefort, "Propriétés thermodynamiques et de transport des plasmas issus de la vaporisation des isolants PTFE et PE , J. Phys. III France 2 (1992) 455 - 472 .

[31] P. André and Z. Koalaga, "Composition of a thermal plasma formed from PTFE with copper in non-oxidant atmosphere. Part II: Comparison of a test case with nitrogen", High Temperature Material Processes 14, 3 (2010) 289.

[32] P. André, L. Brunet, E. Duffour, and J. M. Lombard, "Composition, pressure and thermodynamic properties calculated in plasma formed in insulator vapours of PC and POM at fixed volume", Eur. Phys. J. AP 17, 53-64 (2002).

[33] P. André, L. Brunet, W. Bussière, J. Caillard, J. M. Lombard, and J. P. Picard, "Transport coefficients of plasmas consisting of insulator vapours Application to PE, POM, PMMA PA66 and PC", Eur. Phys. J. Appl. Phys. 25, 169-182 (2004)

[34] P. André and A. Lefort, "The influence of thermal disequilibrium on a plasma consisting of insulator vapours", J. Phys. D: Appl. Phys. 31 (1998) 717-729.

[35] Z. Koalaga, M. Abbaoui et A. Lefort, "Calcul des propriétés thermodynamiques des plasmas d'isolants CHON", I. Phys. D: Appl. Phys. 26 (1993) 393-403.

[36] A. K. Kagoné, "Caractérisation théorique de plasmas thermiques d'arc électrique de mélanges d'air et de vapeur d'eau: Application au disjoncteur basse et moyenne tension", 2012 Thèse de doctorat d'université (Ouaga I Burkina Faso). 